This item was submitted to Loughborough's Research Repository by the author.

Items in Figshare are protected by copyright, with all rights reserved, unless otherwise indicated.

\title{
Quantification of reactivated landslide behaviour using acoustic emission monitoring
}

\section{PLEASE CITE THE PUBLISHED VERSION}

http://dx.doi.org/10.1007/s10346-014-0491-z

\section{PUBLISHER}

(c) Springer-Verlag Berlin Heidelberg

\section{VERSION}

AM (Accepted Manuscript)

\section{LICENCE}

CC BY-NC-ND 4.0

\section{REPOSITORY RECORD}

Dixon, Neil, M.P. Spriggs, Alister Smith, Philip Meldrum, and Edward Haslam. 2019. "Quantification of Reactivated Landslide Behaviour Using Acoustic Emission Monitoring". figshare.

https://hdl.handle.net/2134/14573. 
This item was submitted to Loughborough's Institutional Repository (https://dspace.lboro.ac.uk/) by the author and is made available under the following Creative Commons Licence conditions.

\section{creative
commons}

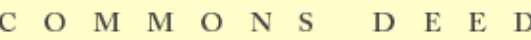

Attribution-NonCommercial-NoDerivs 2.5

You are free:

- to copy, distribute, display, and perform the work

Under the following conditions:

Attribution. You must attribute the work in the manner specified b the author or licensor.

Noncommercial. You may not use this work for commercial purposes.

No Derivative Works. You may not alter, transform, or build upon this work.

- For any reuse or distribution, you must make clear to others the license terms of this work.

- Any of these conditions can be waived if you get permission from the copyright holder.

Your fair use and other rights are in no way affected by the above.

This is a human-readable summary of the Leqal Code (the full license).

\section{Disclaimer 만}

For the full text of this licence, please go to: http://creativecommons.org/licenses/by-nc-nd/2.5/ 
Dixon N, Spriggs MP, Smith A, Meldrum P, Haslam E (2014) Quantification of reactivated landslide behaviour using acoustic emission monitoring. Landslides, pp 12.

DOI: $10.1007 / \mathrm{s} 10346-014-0491-\mathrm{Z}$

\title{
Quantification of reactivated landslide behaviour using acoustic emission monitoring
}

\author{
N. Dixon ${ }^{[1]}$, M.P Spriggs ${ }^{[1]}$, A. Smith ${ }^{[1]^{*}}$, P. Meldrum ${ }^{[2]} \&$ E. Haslam ${ }^{[2]}$
}

${ }^{[1]}$ School of Civil and Building Engineering, Loughborough University, Leicestershire, UK

${ }^{[2]}$ British Geological Survey, Keyworth, Nottinghamshire, UK

*Corresponding author. E-mail: a.smith10@lboro.ac.uk

\begin{abstract}
Slope failures world-wide cause many thousands of deaths each year and damage built environment infrastructure costing billions of pounds to repair, resulting in thousands of people being made homeless and the breakdown of basic services such as water supply and transport. There is a clear need for affordable instrumentation that can provide an early warning of slope instability to enable evacuation of vulnerable people and timely repair and maintenance of critical infrastructure. An approach, Assessment of Landslides using Acoustic Real-time Monitoring Systems (ALARMS) is described in the paper and results of a field trial of sensors on an active landslide at Hollin Hill, North Yorkshire, UK, are described. Continuous and real-time monitoring of acoustic emission generated by the deforming slope has been compared to traditional inclinometer slope displacement measurements. Analysis of the results has established that there is a direct relationship between acoustic emission rate and displacement rate trends triggered by rainfall events. The technique has provided insight into reactivated slope movement kinematics.
\end{abstract}

Keywords: Acoustic Emission (AE), Reactivated Landslide, Deformatons, Instrumentation 


\section{Introduction}

Slope failures world-wide cause many thousands of deaths each year (e.g. Petley (2012) reported records of over 32000 fatalities globally that occurred as a result of landslides during the period 2004 to 2010) and damage built environment infrastructure, costing billions of pounds to repair, resulting in thousands of people being made homeless and the breakdown of basic services such as water supply and transport. The large majority of deaths from slope failures occur in countries located in tropical regions (e.g. South East Asia and Central America), triggered by extreme rainfall, and in earthquake prone regions. The United Nations International Strategy for Disaster Risk Reduction (UN-ISDR) through the Hyogo Framework for Action 2005-2015 Building the Resilience of Nations and Communities to Disasters (adopted at the UN Conference on Disaster Reduction, Japan 2005) has produced a five point action plan. The second element of this plan is 'Identify, assess and monitor disaster risks and enhance early warning'. Specific gaps and challenges identified include the need to develop early warning systems whose warnings are timely and understandable to those at risk.

In countries located in temperate climates, fatality rates are lower; however the impact on performance of infrastructure and cost of repair is high. In the UK, fatalities from slope failures are rare, but the current cost of unstable slope management is known to be considerable, although not quantified. Instability of both natural and constructed slopes presently has a significant impact on the built environment and infrastructure in the UK with many tens of thousands of people living with slope instability (e.g. Ventnor, Lyme Regis and parts of London and Edinburgh). Tens of thousands of kilometres of transport links and utilities are located in areas susceptible to failure of natural slopes. In addition, there are $20,000 \mathrm{~km}$ of earthworks (i.e. cuttings and embankments) the failure of which has a major detrimental effect on the UK's infrastructure as demonstrated by the disruption of road and rail networks resulting from the many slope failures that occurred during periods of high precipitation. There is growing concern that global change, in the form of climate change and increased population concentrated in urban areas, will result in a rise in the number and magnitude of slope failures causing fatalities, particularly in low and middle income countries. In developed countries, climate change and the ageing infrastructure is anticipated to lead to increasing frequency of slope failures causing disruption to services and increased cost of maintenance. 
The need for affordable instrumentation that can be used to provide an early warning of slope instability to enable evacuation of vulnerable people and timely repair and maintenance of critical infrastructure is self-evident. Current systems are either too expensive for widescale use or have technical limitations. An approach, Assessment of Landslides using Acoustic Real-time Monitoring Systems (ALARMS) based on detecting and quantifying acoustic emission generated by deforming soil slopes has been developed and trialled using unitary battery operated sensors. This paper extends Dixon et al. (2010), which introduced the instrumentation approach, and Dixon et al. (2012), which presented preliminary results from the initial period of monitoring at the Hollin Hill landslide. This paper presents the extended acoustic monitoring programme for this site and provides a detailed discussion comparing acoustic behaviour with traditional deformation measurements. The paper focuses specifically on $\mathrm{AE}$ monitoring of soil slopes, $\mathrm{AE}$ monitoring of rock slopes can be found elsewhere in the literature (e.g. Lockner 1993).

\section{Acoustic emission monitoring of soil slopes}

\subsection{Background}

Materials undergoing deformation generate acoustic stress waves (also known as acoustic emission (AE) and sub-audible noise). Studies of AE aim to use the capture and measurement of the signal to determine the extent of material deformation. In soil, AE is generated from inter-particle friction and in rock by fracture propagation and displacement along discontinuities (also termed microseismic and rock noise). Acoustic emission can be detected using suitable transducers to provide information on the presence and location of straining.

Acoustic emission monitoring is not a new technique in geotechnical applications. It has been described in standard texts on geotechnical instrumentation (e.g. Dunnicliff 1988) and on landslide investigation (e.g. Schuster \& Krizek 1978), although considerable scepticism has existed regarding practicality of the technique. Stability of soil and rock slopes has been studied using AE techniques for over 50 years by international researchers, although the low energy and high attenuation of AE in soil has hindered production of a viable field system. The most significant contribution in the area of $\mathrm{AE}$ behaviour of soil has been made by Koerner et al. (1981) who carried out extensive laboratory and field studies of both fundamental AE characteristics of soil and field applications. This work demonstrated that deforming soil produces detectable $\mathrm{AE}$ and that the levels of emissions are directly related to the stress state of the soil. More recently, a number of researchers in Japan have been active 
in soil AE research (e.g. Fujiwara et al. 1999, Shiotani \& Ohtsu 1999), and in Switzerland (e.g. Michlmayr et al. 2012 and Michlmayr et al. 2013). This body of international research has demonstrated that acoustic emission is generated during soil slope movements and that AE monitoring is capable of detecting pre-failure deformations. However, interpretation of acoustic emission data has previously been only qualitative.

Dixon et al. (2003) and Dixon \& Spriggs (2007) report research to develop a quantitative solution to this problem. Dixon et al. (2003) describe an approach using AE monitoring of active waveguides. In order for a stress wave to travel through a soil mass it must pass from particle to particle. When mechanical wave energy strikes the boundary between two particles a proportion of the energy will be transmitted in to the second particle while the rest is reflected back into the original particle (Pollard 1977). Soil therefore attenuates high levels of energy over short distances and this necessitates the implementation of the waveguide. The low magnitude signals and high attenuation attributed to the quiet cohesive soils that are found within many slopes, necessitates the introduction of sources of increased AE activity. The 'active' waveguide is installed in a borehole that penetrates stable stratum below any shear surface or potential shear surface that may form beneath the slope. The active waveguide comprises a metal waveguide rod or tube that provides a low resistance path for AE signals to travel from the source to the sensor at the ground surface. The annulus surrounding the waveguide is backfilled with granular 'noisy' soil. When the host soil slope deforms, the column of granular soil also deforms and this induces relatively high levels of AE that can propagate along the waveguide. The AE produced from this system does not relate directly to the stress state of the host soil, however, through calibration of the system it is possible to relate $\mathrm{AE}$ behaviour of the soil column with deformations of the ground. $\mathrm{AE}$ in the active waveguide system is induced by a variety of mechanisms: straining of the metal waveguide directly (i.e. in bending); shearing at the interface between the backfill and the waveguide; and compression and shear within the backfill material (i.e. inter-particle friction). Koerner et al. (1981) and Dixon et al. (2003) found that AE generated by soil is influenced by particle size and shape, with larger more angular particles generating greater amplitude stress waves as a greater magnitude of work is required to overcome interlock. Other properties that influence the AE response of soil include; grading, moisture content and plasticity. Angular gravel aggregate is usually selected as active waveguide backfill due to the relatively high magnitude signals that they produce. 
Dixon et al. (2003) proved that AE monitoring of active waveguides has the potential to detect pre-failure deformations earlier than conventional inclinometers. Dixon et al. (2003) carried out a field trial in a brick pit at Arlesey, Bedfordshire, England. A slope $4.5 \mathrm{~m}$ high formed of Gault Clay was instrumented with active waveguides and inclinometer casings. Slope instability and deformation was induced by stress relief, through excavating successive slices from the toe. Elevated levels of $\mathrm{AE}$ measured from active waveguides were detected subsequent to excavation phase 4 while measurements from surveys of the inclinometer casings showed no change until after excavation 5. Dixon et al. (2003) also monitored the failure of a coastal slope at Cowden, north-east England, using active waveguides and conventional inclinometers. Not only did this case study demonstrate that AE energy increased throughout the failure event as the rate of displacement increased, but that $\mathrm{AE}$ continued to generate beyond deformation magnitudes sufficient to shear off inclinometer casings and render them unusable.

Dixon \& Spriggs (2007) found that by applying displacement rates that were separated by orders of magnitude (i.e. slow, moderate and rapid as in Transportation Research Board (1978)) to active waveguide models with gravel backfill in the laboratory, the magnitude of AE rates generated were also separated by orders of magnitude, and proportional to the displacement rate applied. This research demonstrated for the first time that AE monitoring can be used to give a quantification of slope movement rates. The system was also shown to be sensitive to changes in displacement rate, making the technique suitable for detection of changes in relative slope stability in response to destabilising (e.g. climate related) and stabilising (e.g. remediation) events.

\subsection{The Slope ALARMS system}

Historically, a key limitation on the use of the AE technique has been the cost and complexity of the monitoring instrumentation and the need for secure instrument housing and mains electricity. In order to make AE slope monitoring relevant for a range of applications and accessible to users, it became apparent that a simpler low cost system is required. This limitation has now been removed through the conception of a unitary battery operated realtime acoustic emission slope displacement rate sensor called Slope ALARMS (Dixon \& Spriggs 2011). This comprises a piezoelectric transducer, pre-amplifier, filters, signal processing, data storage and power supply. Various parameters can be determined from the AE waveform (i.e. peak amplitude, rise time, envelope and area under the curve). In order to 
reduce the amount of processing power and storage capacity required from a battery operated sensor, the decision was made to record ring down counts (RDC). RDC are the number of times the signal amplitude crosses a programmable voltage threshold level within a predetermined time period. Previous research has shown that changes in strain rates results in proportional changes in RDC rates; a notable work being Dixon \& Spriggs (2007). Ring down counts (RDC) will be used as the AE measurement unit throughout this paper. Research sensors based on this design and incorporating wireless communication have been designed and produced by the British Geological Survey (BGS) in collaboration with Loughborough University and they are being used in a number of proof-of concept trials in the UK, Italy and Canada.

The AE sensor is located on the active waveguide, which comprises a steel tube installed in a gravel filled borehole constructed into a potentially unstable soil slope (Figure 1). The waveguide length can be many tens of metres long, with the length dictated by the need to intersect potential shear surfaces that may form beneath the slope. Acoustic emissions are generated as the straining soil slope deforms the gravel backfill in the borehole and are transmitted to the ground surface by the steel waveguide. In real-time, generated AE are recorded at pre-defined time intervals. Measured AE rates are the number of times in each time period (i.e. 15, 30 or 60 minutes) that the detected signal exceeds a pre-determined threshold (i.e. a RDC). RDC are used to derive displacement rates accurate to an order of magnitude, which is in line with current practice for classifying slope movements (Transportation Research Board 1978).

A key design aspect of the AE approach is the use of filters to focus AE detection within the frequency range of 20 to $30 \mathrm{kHz}$ to eliminate environmental noise such as generated by wind, traffic, humans and construction activities. Recorded AE rates (RDC/hour) are compared to pre-determined trigger/action values. If a trigger value is exceeded, an alert message is communicated to a nominated person(s) to enable relevant action to be taken.

Nakajima et al. (1991), Maji et al. (1997) and Spriggs (2005) describe methods to determine the distance to the source of $\mathrm{AE}$ along a waveguide. By measuring the differences in arrival times of different wave modes, and by knowing the propagation velocity of the different wave modes, the distance to the source of emissions (i.e. the shear surface) can be determined from the displacement/time relation. The current Slope ALARMS system which is described in this paper records the number of times the amplitude of the waveform crosses 
a pre-determined voltage threshold within a set time period, and therefore does not record the entire waveform and cannot distinguish arrival times of different wave modes. Source location (i.e. determination of the depth of the shear surface) is not a capability of the current Slope ALARMS sensor due to the necessity to minimise processing power and maximise data storage, however, this would be possible if the entire waveform was recorded.

\section{Hollin Hill field trial of AE monitoring technique}

\subsection{Introduction}

In order for any new instrumentation to be accepted by users there is a need to compare performance against traditional well established techniques, which for slope monitoring is invariably inclinometer based systems. In this study, comparison is required to demonstrate the $\mathrm{AE}$ instrument is robust and can operate in the field environment, that it is capable of detecting deformation rates commonly measured using inclinometers and that there are benefits in using the new AE technique, such as improved performance (i.e. sensitivity) and reduced cost. A slope early warning system should provide sufficient warning to enable action to be taken (i.e. implement an emergency plan), it must be robust so that false alarms are not generated as this undermines confidence and also provide information on rates and magnitude of movement so that likelihood and significance of failure events can be determined. In addition, it should allow the mode of failure to be identified so that the significance of a failure event can be assessed. An active landslide at Hollin Hill (Figure 2) was selected for the trial as in recent years slope deformations have occurred during the winter months and there was confidence that measurable slope deformations would be experienced during the monitoring period. The BGS have used this site to assess development and performance of other novel instrumentation such as a permanent electrical resistivity tomography (ERT) and self-potential (SP) geophysical and geotechnical system for monitoring spatial and temporal behaviour (Chambers et al. 2008; Chambers et al. 2011; Merritt et al. 2013).

\subsection{Site geology and hydrogeology}

The Hollin Hill research site [SE 6812268852 (UK system), Latitude: 54.111044, Longitude: -0.95948786] lies $11 \mathrm{~km}$ to the west of Malton, North Yorkshire, UK, occupying an elevation of between $55 \mathrm{~m}$ and $100 \mathrm{~m}$ AOD. The site is located on a south facing valley side with a slope of approximately $12^{\circ}$. The bedrock geology, from the base to top of slope, comprises the Lias Group Redcar Mudstone Formation (RMF), Staithes Sandstone and 
Cleveland Ironstone Formation (SSF), and Whitby Mudstone Formation (WMF), which are overlain at the top of the hill by the Dogger Sandstone Formation (DF). The bedrock is relatively flat lying with a gentle dip to the north. Slope failure at the site is occurring in the weathered WMF, which is highly prone to landsliding. The landslide is characterized by shallow rotational failures at the top of the slope that feed into larger-scale slowly moving lobes of slumped material (Figures $2 \mathrm{a}$ and $2 \mathrm{~b}$ ); the rotational features and active lobes extend approximately $150 \mathrm{~m}$ down the slope from the top of the hill, and extend laterally more than 1 $\mathrm{km}$ along the valley side. In recent years, movement of the lobes has been in the order of tens of centimetres per annum. Movement typically occurs in the winter months (i.e. January and February) when the slope is at its wettest. During this period, water can be observed accumulating in the basins caused by rotational slips towards the top of the slope, and can be seen emerging from the toe of the lobes. Drainage from the site also occurs along a spring line at the base of the SSF, where groundwater appears to be running off the surface of the less permeable underlying RMF. Piezometers have revealed elevated pore pressures at the failure planes within the slipped WMF and at the interface between the slipped WMF material and the underlying SSF.

A detailed description of the site is provided by Chambers et al. (2011) and Merritt et al. (2013) who have reported on the use of geophysical, remote sensing and geotechnical methods for the development of a 3D ground model of the Hollin Hill landslide complex. GPS surveys of peg positions, airborne LiDAR, and ERT have been used to identify and characterise a series of rotational slumps in the mid- to upper- regions of the slope that feed into the flow lobes that activate simultaneously. Core logging results demonstrated that the flow deposits give way to rotational slump deposits with increasing depth beneath the slope. This boundary between flow and slump deposits was also detected by the ERT due to a reduction in resistivity at a transition in lithology as the fines content increased from $30 \%$ to $70 \%$.

Gunn et al. (2013) report results from borehole core logging of the flow lobes at Hollin Hill. Logging from a borehole at the location of Cluster 2 in Figure 3 details the material in the vicinity of the shear surface (at roughly $1.5 \mathrm{~m}$ below ground level as shown in Figure 6). The section of material below the top soil $(0.2 \mathrm{~m}$ to $1.6 \mathrm{~m}$ below ground level) was described as a flow deposit with a very loose, porous fabric comprising orange-brown, very soft, silty clay with occasional blue-grey streaks. The unit had penetration resistances of $1 \mathrm{MPa}$ or less. The unit from $1.6 \mathrm{~m}$ to $3.4 \mathrm{~m}$ was described as a matrix of stiff, brown-grey clay with 
subangular, fine $(5 \mathrm{~mm})$ to coarse $(40 \mathrm{~mm})$ gravel-sized relic lithoclasts of dark brown, interlaminated claystone and siltstone. The penetration resistance throughout this unit was roughly $2 \mathrm{MPa}$ or less. The unit from $3.4 \mathrm{~m}$ to $4.8 \mathrm{~m}$ (the depth of the second shear surface on the eastern lobe at Cluster 3 sits at roughly $4 \mathrm{~m}$ below ground level as described in section 3.5) was described as a compact light orange-brown to red-brown silt matrix with many orangered, angular, fine to medium $(20 \mathrm{~mm})$ gravel-sized ironstone nodules (suspected to be degraded siderite). This unit had relatively high penetration resistances of over $7 \mathrm{MPa}$. The unit below $4.8 \mathrm{~m}$ was described as uncompact clayey silt with occasional subangular fine to coarse gravel of siderite nodules, and this unit had penetration resistances between $3 \mathrm{MPa}$ and $4 \mathrm{MPa}$.

\subsection{Installation of AE waveguides and inclinometer casings}

Three clusters of active waveguides and inclinometer casings have been installed through two of the lobes (Figures 3 and 4). The waveguides were installed in $130 \mathrm{~mm}$ diameter holes to depths of $5.7 \mathrm{~m}$ below ground level. The waveguides comprise two $3.0 \mathrm{~m}$ lengths of 50 $\mathrm{mm}$ diameter $3 \mathrm{~mm}$ thick steel tubing connected with screw threaded couplings. The annulus around the steel tubing, which is located in the centre of the borehole, is backfilled with angular $5 \mathrm{~mm}$ to $10 \mathrm{~mm}$ gravel compacted in nominally $0.25 \mathrm{~m}$ high lifts. The top $0.3 \mathrm{~m}$ of the borehole is backfilled with a bentonite grout plug to seal against the ingress of surface water. The steel tube extends $0.3 \mathrm{~m}$ above ground level and is encased in a secure protective chamber. Inclinometer casings were installed approximately $1.0 \mathrm{~m}$ from the waveguides with keyways orientated along the slope dip and strike directions. The inclinometer casings penetrate to depths of $6 \mathrm{~m}$ to $7 \mathrm{~m}$ below ground level and the annulus around the casing is grouted using medium stiffness cement bentonite grout.

\subsection{Acoustic emission sensor}

A unitary $\mathrm{AE}$ sensor is located inside the protective cover (Figures $5 \mathrm{a}$ and $5 \mathrm{~b}$ ). A piezoelectric transducer is attached to the waveguide and linked to the sensor via a cable. The AE sensor is powered by a battery, which is recharged by a solar panel (Figure 4). Monitoring is continuous.

Cumulative AE ring down counts (RDC) are recorded and time stamped for each monitoring period. Monitoring commenced at this site on 15th December 2009 at Cluster 2 and has been continuous apart from short periods of down-time due to battery failure. Monitoring at Clusters 1 and 3 commenced in February 2010 and continued until December 
2010 when the sensors were removed for use on another site. A new sensor was installed at Cluster 3 which became operational again in November 2012. A recording period of 15 minutes was used for all instruments until 2012 when it was changed to 30 minute to extend the time for the logger to reach storage capacity. Initially, the data was downloaded from the sensors manually during weekly site visits at which the inclinometer casings were surveyed. However, a wireless coordinator unit was installed in summer 2010 and this has provided remote access to the sensors enabling remote downloading of the AE data. It also provided a facility for real-time communication to mobile phone via automated text messages of $\mathrm{AE}$ rates based on pre-set thresholds being exceeded.

\subsection{Deformation history}

In an ideal situation performance of the AE sensors would be evaluated by comparing the time history of $\mathrm{AE}$ measurements with a continuous time history of deformation measurements. Unfortunately traditional in-place inclinometers or newer ShapeAccelArray (SAA) instruments required to obtain continuous subsurface deformations are relatively expensive and could not be afforded for this study. In fact this high cost is one of the primary motivations for developing Slope ALARMS as it is anticipated that the sensors could provide a cheaper real-time monitoring alternative. During the first part of 2010 the inclinometer casings were surveyed weekly in an attempt to define periods of slope movement as precisely as possible. The reading frequency was decreased during periods when slope movements were unlikely to occur due to relatively drier weather.

The inclinometer surveys show that the shear plane at Clusters 1 and 2 is relatively shallow at $1.0 \mathrm{~m}$ to $1.5 \mathrm{~m}$ below ground level on the western lobe (Figure 6). Inclinometer data from the eastern lobe (Cluster 3 ) shows active shear surface deformation at two depths; $1.5 \mathrm{~m}$ and $4.0 \mathrm{~m}$ below ground level. A number of deformation events were identified in February 2010 at the end of the winter period when the slope was at its wettest. Following 18 months of unusually dry weather in 2010 and 2011 when the slope was stable, deformations were next recorded in 2012 in response to a period of high precipitation during the summer months. Continued precipitation caused further slope movements with the inclinometer casings recording substantial slope deformations in November 2012. These deformations induced excessive curvature of the casings and the probe could no-longer pass and hence the casings became unusable and inclinometer measurements ceased. A decreased frequency of 
inclinometer surveys in 2011 and 2012 mean that the deformation measurements have a low temporal resolution for this period.

\subsection{Acoustic emission history}

As stated in section 2.2 the units of acoustic emission used in this study are ring down counts (RDC); AE rates have units RDC per hour (RDC/hour), AE energy has units RDC (total RDC generated throughout the deformation event), and cumulative RDC is the accumulation of RDC throughout the time series.

Figure 7 shows cumulative RDC for Cluster 2, rainfall per hour and the cumulative inclinometer displacements at a depth of $1 \mathrm{~m}$ during the first few months of 2010. Of note are the steep increases in the cumulative RDC record, labelled Events A and B, which follow intensive periods of rainfall. The combination of antecedent moisture being accumulated over long periods (i.e. typically during the winter) and a relatively shallow shear surface $(1.0 \mathrm{~m}$ to $1.5 \mathrm{~m}$ ) mean that short periods of intense rainfall cause a build-up of pore water pressures in the region of the slip surface, inducing short periods (see Section 3.7) of reactivated slope movements on the existing shear surface. Such renewals of movement on pre-existing shears are expected to be of modest speed and travel as the strength is already at, or close to, the residual value and therefore little further loss of strength can occur, and the stress-strain behaviour is non-brittle in nature (Hutchinson 1988; Leroueil 2001). The ' $S$ ' shaped increases in cumulative RDC (Figure 7) are interpreted as defining periods of slope deformation and this is validated by the inclinometer measurements. Other similar events recorded at the three clusters are interpreted in the same way and it is hypothesised that $\mathrm{AE}$ time relationships can be used as a measure of the timing and rate of slope displacements. As continuous measurements of deformation were not available, it is an assumption at this time that the steps in cumulative RDC give the timing of the slope movements. This hypothesis has being tested and validated at other sites where continuous slope deformations have been measured using in-place inclinometers. The existence and timing of the events at Hollin Hill, along with confirmation of movements from inclinometer measurements, is consistent with, and hence supports, the AE/slope displacement behaviour observed at other sites. For example, following periods of rainfall measurements at Clusters 1 and $2 \mathrm{AE}$ events occur at exactly the same time, which is expected as they are located on the same lobe of the landslide. Events have also been identified to occur on Cluster 3 (eastern lobe) at similar times to Clusters 1 and 2 (western lobe). Merritt et al. (2013) also identified simultaneous activations of slope 
movement from multiple flow lobes at this site. This is expected due to the similarity in materials, geometry and boundary conditions between the flow lobes. In addition, RTK-GPS surveys of pegs shown in Merritt et al. (2013) have recorded movements of the flow lobes at Hollin Hill over the same period of AE monitoring, although with lower temporal resolution.

\subsection{Deformation event AE signature}

Figure 8 shows Event $\mathrm{A}$ at a larger scale. It can be seen that the $\mathrm{AE}$ generation is triggered by a preceding rainfall event. The $\mathrm{AE}$ rate (RDC/hour) rapidly increases, denoted by the slope of the cumulative RDC vs. time relationship, and then slowly decreases, giving a characteristic ' $S$ ' shaped curve. This shape is produced by the large majority of the AE events that are generated by reactivated slope deformations at Hollin Hill. Displacement-time relationships for slope movement patterns are reported to exhibit similar ' $\mathrm{S}$ ' shaped curves (e.g. Allison \& Brunsden 1990, Petley et al. 2005 and Massey et al. 2013). Such reactivated slope kinematics are explained by an initial acceleration of the slide mass due to increasing pore water pressures on the shear plane, and hence reducing shear strength and stability, and a peak velocity is approached. This is followed by a deceleration of movements as pore water pressures dissipate and due to mobilisation of shear resistance internally in the slide mass and through remoulding at the landslide toe.

The AE ring down count rate per hour for Event $\mathrm{A}$ is shown in Figure 9. The log normal bell shaped relationship is produced by the ' $\mathrm{S}$ ' shaped cumulative RDC measurements and is typical of the events monitored. The shape of the AE rate-time curve for the deformation event is indicative of acceleration followed by deceleration of slope movements and hence it is analogous to a velocity profile. A gradual reduction in $\mathrm{AE}$ rate occurs as slope movement and therefore waveguide backfill deformation ceases. Leroueil (2001) presented a conceptual velocity-time profile for the 'reactivation stage' of slope movements that possessed the shape of a normal distribution, and hence velocity is expected to increase exponentially with time during reactivated slope movements until a peak velocity is reached and the velocity subsequently decays exponentially until movement ceases. AE rate (RDC/hour)-time relationships for deformation events at Hollin Hill are analogous to such behaviour; however the $\mathrm{AE}$ measurements demonstrate that the velocity profiles for reactivated slope movements at the Hollin Hill site are predominantly log normal in shape. This indicates that 'slip' during the onset of movement accelerates the sliding mass to a peak velocity at a faster rate when compared to the rate at which the sliding mass can mobilise resistance and decelerate to 
equilibrium. AE monitoring by Fujiwara et al. (1999) of an embankment slope failure also produced log normal AE rate vs. time relationships.

Analysis is based on the premise that event $\mathrm{AE}$ rates produced from the system are proportional to the velocity of slope movement; a relationship that is described in Dixon \& Spriggs (2007). The coefficient of proportionality defines the systems sensitivity (i.e. the magnitude of $\mathrm{AE}$ rates ( $\mathrm{RDC} / \mathrm{hour}$ ) generated in response to an applied velocity) and is dependent on many variables related to the $\mathrm{AE}$ measurement system such as: the sensor sensitivity controlled by signal amplification and voltage threshold; the depth to the shear surface that influences the magnitude of $\mathrm{AE}$ signal attenuation as it is transmitted from the shear zone to ground surface by the waveguide; and active waveguide properties such as the tube geometry and backfill properties. The magnitude of AE rate responses produced by each measurement system will depend on these factors, in addition to the rate of slope displacement. This variability in system characteristics currently necessitates individual attention to each system when calibration is conducted and slope displacement rates are quantified. Calibration is conducted through a laboratory derived AE rate-velocity relationship, where the coefficient of proportionality is indicative of system sensitivity. Individual system calibration will be required until a time when the influence of each variable upon the coefficient of proportionality can be quantified and modelled, and a generic calibration method is developed. This work is being carried out currently at Loughborough University.

\section{Interpretation of measured behaviour}

\subsection{Event energy and displacement}

As continuous slope deformation data was not available, determination of slope velocity profiles for direct comparison with $\mathrm{AE}$ rate profiles was not possible. Therefore, to validate the assumption that $\mathrm{AE}$ rates are proportional to slope velocity, relationships between $\mathrm{AE}$ event energy and the magnitude of slope movement were investigated. The AE event energy was determined from the area under the $\mathrm{AE}$ rate bell shaped curves using trapezoidal integration (Equation 1) as the curves are formed of a series of data points which allows accurate interrogation using trapezoids.

Area $=\int_{a}^{b} f(x) d x \approx \sum(b-a) \frac{f(a)+f(b)}{2}$ 
The total RDC produced during an event was used as a measure of the deformation event AE energy. These energy values were compared to the magnitude of inclinometer measured deformation over the same period for the shear surface depth. Deformation data was taken from $1 \mathrm{~m}$ depth on the western lobe (Clusters 1 and 2). The inclinometer data from the eastern lobe (Cluster 3) indicated two shear surfaces at $1.5 \mathrm{~m}$ and $4 \mathrm{~m}$ depths and therefore the magnitude of deformation used in the analysis of each event was the sum of both shear surface displacements. If $\mathrm{AE}$ rates and slope velocities are proportional; the relationship between the AE energy (i.e. total RDC) and the total slope displacement for each event should also be proportional. As described in Section 3.7, differences between system characteristics mean that events produced by each measurement system are not likely to be the same, although trends of behaviour will be comparable. The events analysed and presented were taken from monitoring periods during which the sensor sensitivity (i.e. voltage threshold level) was constant.

Figure 10 shows the energy-displacement relationship, plotted log-log, for four events that occurred at Cluster 2 during 2010. Deformation events of greater magnitude produced proportionally greater AE energy.

The effect of sensor sensitivity changes (i.e. through changes to the voltage threshold level) was investigated during the period of monitoring, the results of which demonstrated that changes in sensitivity can yield order of magnitude changes in output $\mathrm{AE}$ rates from the same sensor/waveguide system. Some slope deformation events occurred during such periods of altered sensitivity and therefore the $\mathrm{AE}$ data from these were not representative of the energy produced from other events, and are not used in this analysis. The varying sensitivities between the systems on different clusters mean that the results are not directly comparable; however, a general positive relationship is demonstrated in Figure 11. The results plotted on logarithmic scales demonstrate that an order of magnitude increase in event deformation yields an order of magnitude increase in the AE event energy produced. It should be noted that the magnitude of events are relatively small due to the slope being a reactivation on an already defined shear surface. This means that the slope velocities experienced are also relatively small. The ability of AE monitoring to detect such small magnitude displacements and displacement rates provides confidence in the technique for use as an early warning system. 


\subsection{AE rate- and velocity- time deformation event profiles}

Demonstration that that energy and displacement are proportional to one another supports the hypothesis that $\mathrm{AE}$ rates are proportional to slope velocities. $\mathrm{AE}$ rates (RDC/hour) are the derivative of energy (RDC) with respect to time (hours), and velocity is the derivative of displacement with respect to time. Therefore, using the shape of the AE rate-time profile it is possible to determine a velocity-time profile for a slope movement event by equating the area under the AE rate-time curve to the magnitude of displacement. The total event displacement was distributed proportionately to each trapezoidal integrand (Equation 2).

Proportion of event displacement in trapezoid $(\mathrm{mm})=$ Total event displacement $(\mathrm{mm}) \times$ Proportion of event energy in trapeziod $(R D C) /$ Total event energy $(R D C)$

This allowed the velocity over each trapezoid under the curve to be determined from the displacement/time relation (Figure 12, Equation 2 and Equation 3).

Area of trapezoid $=$ Displacement $(\mathrm{mm}) \therefore$ Velocity $(\mathrm{mm} /$ hour $)=\frac{\text { Displacement }(\mathrm{mm})}{T_{2-} T_{1}(\text { hour })}$

This enables a velocity-time curve, proportional to the $\mathrm{AE}$ rate -time curve, to be produced for each displacement event by using the magnitude of displacement at the shear surface measured by the inclinometer for the period in which the event occurred. The sporadic nature of the AE rate data is due to slip-stick deformations taking place between the gravel particles within the backfill as interlock is overcome and regained. Indeed it would be assumed that the velocity-time profile of the slope movement would be a smoother curve of moving averaged values. Interrogation of the velocity profile for Event A in Figure 13 yields an event duration of roughly 60 hours, with a peak velocity of $0.16 \mathrm{~mm} /$ hour and an average velocity of $0.05 \mathrm{~mm} /$ hour. This event would be classified as 'very slow' according to Transportation Research Board (1978). Of particular interest is the apparent sensitivity of the AE technique to changes in low magnitude slope velocities. As the strength along the slip surface is already at, or close to, the residual value the low magnitude velocities illustrated in Figure 13 were expected and are characteristic of a reactivation on an already defined rupture surface. For example, Schulz et al. (2009) described how the Slumgullion Landslide displayed daily movement patterns where increased velocity seemingly coincided with the diurnal low tides of the atmosphere as changes in air pressure altered the frictional resistance along the shear surface leading to daily velocity cycles that have a peak of roughly 2$3 \mathrm{~mm} /$ hour, and Matsuura et al. (2008) reported the monitoring of a reactivated landslide 
under constant creep in Japan that experienced an average hourly displacement of $0.7 \mathrm{~mm}$. The ability of the technique to detect small changes of slope velocity in real-time demonstrates promise as an early warning system.

Each point in time throughout the event shown in Figure 13 has both a corresponding $\mathrm{AE}$ rate and a velocity. Hence a calibration AE rate -velocity relationship (Figure 14) can be produced for that specific monitoring system, and this can be used to derive slope displacement velocities from the measured $\mathrm{AE}$ rate that occur in response to subsequent deformation events. There is the potential to do calculations in real-time if the calibration relationship is included in an algorithm within the sensor architecture. Such a calibration could be produced in the laboratory prior to installation in the field. A generic calibration technique that quantifies the influence of all variables that yield changes in AE rate outputs could also be produced.

Of interest is the coefficient of proportionality, or gradient, ' $\mathrm{m}$ ' in Figure 14. This is dependent on the characteristics of the measurement system used, which dictates the magnitude of $\mathrm{AE}$ rate produced in response to an applied velocity (i.e. the systems sensitivity). The coefficient of proportionality is influenced by many different variables as discussed in Section 3.7 (i.e. voltage threshold on sensor, depth to the shear surface and attenuation characteristics of the active waveguide etc). In the study at Hollin Hill the coefficient was different for each monitoring system that was used. The calibration relationships for the three clusters and their sensor settings are shown in Figure 14. It can be seen that Cluster 2 (2010) has the greatest 'sensitivity', as a greater magnitude of AE rates were produced in response to a given applied slope velocity. Cluster 2 (2012) had the lowest 'sensitivity' by contrast.

The respective relationships shown in Figure 14 were used to obtain slope movement velocities from subsequent events that occurred while the systems operated with the same settings and configuration. As continuous deformation data was not available, only average velocities could be compared. The average $\mathrm{AE}$ rate over each deformation event was converted to an average velocity using the calibrations in Figure 14 (i.e. 'calculated'). The 'actual' average velocity was determined from inclinometer data and event duration using the displacement/time relationship. The 'calculated' and 'actual' values were compared to provide validation and an indication of accuracy of velocity interpretations through the use of the $\mathrm{AE}$ rate -velocity calibration approach. Eight events were selected for this part of the analysis, and are numbered in Figure 15 in no particular order. The results are shown in 
Figure 15 on a logarithmic scale, which demonstrates that the procedure produced errors of less than an order of magnitude (i.e. the difference between 'actual' and 'calculated' velocity). Standard assessment for landslide classification uses order of magnitude accuracy and hence the results presented in Figure 15 demonstrate the potential of an AE system to provide this level of information. An example of how the calibration equation was used for interpretation of displacement rates from $\mathrm{AE}$ rate is shown in Equation 4.

$$
y=m x, \text { where }
$$

$y=A E$ rate $\left(\frac{R D C}{\text { hour }}\right), x=\operatorname{Velocity}\left(\frac{\mathrm{mm}}{\text { hour }}\right)$, and $m=$ Coefficient of proportionality

$\therefore$ Velocity $=\frac{A E \text { rate }}{\text { Coefficient of proportionality }}$

Possible explanations for the error margins produced from the analysis include: underestimation of event duration (when calculated<actual); overestimation of event duration (when calculated>actual); and the occurrence of significant background noise (when calculated>>actual) due to environmental factors (i.e. temperature extremes) or electromagnetic noise. The bell shaped AE rate-time curve for Event No 1 appeared to be superimposed with sporadic background noise; this made it difficult to determine the start and end of the deformation event. Background noise combined with the possible over estimation of event duration could contribute to the 'calculated' average velocity being greater than the 'actual'.

\subsection{Deformation pattern interpretation from $\mathrm{AE}$}

Figure 16 illustrates how the AE data can be used to produce continuous cumulative deformation data for Event A on the western landslide lobe based on the calibration at Cluster 2. The velocity-time profile produced from the AE data was used to determine the cumulative displacement throughout the deformation event. This approach provides temporal resolution for the cumulative inclinometer data and demonstrates the potential of continuous $\mathrm{AE}$ monitoring using technology such as Slope ALARMS sensors to deliver real-time deformation rate information, as an alternative to traditional in-place inclinometers or SAA. Figure 17 shows the AE rates measured at each of the three clusters in response to a period of rainfall. The AE monitoring shows that all three locations became unstable and experienced similar cumulative displacement magnitudes and rates. 


\section{Summary}

The paper introduces the concept of using acoustic emission monitoring to assess stability of soil slopes. International research over the past 50 years has demonstrated that deforming soil slopes generate detectable $\mathrm{AE}$ and that $\mathrm{AE}$ rates are proportional to displacement rates. Previous research by the Authors has developed a monitoring system using active waveguides and an associated processing procedure that employs quantified AE rates to measure slope displacement rates. Operation of a unitary AE sensor is detailed in the paper, which can be used to provide relatively low cost continuous real-time slope monitoring. The AE sensor is being trialled on an active landslide at Hollin Hill, North Yorkshire, UK, where performance is compared to traditional inclinometer slope displacement measurements. Results indicate that there is a direct relationship between $\mathrm{AE}$ rates (ring down counts per hour) and displacements. Increased $\mathrm{AE}$ rates following rainfall events are indicative of slope displacements. Slope deformation events have a characteristic ' $S$ ' shaped cumulative RDC vs. time relationship indicating initial acceleration followed by deceleration of the slide body.

It has been demonstrated that $\mathrm{AE}$ rates are proportional to the velocity of landslide movement and this relationship has been used to obtain velocity profiles during slide events. Although each measurement system has a specific sensitivity, and hence relationship between $\mathrm{AE}$ and displacement, it has been shown that order of magnitude changes in displacement magnitude and rate can be differentiated when monitoring AE. Consistent and comparable AE trends are obtained over time in response to landslide movements for a given sensor, and also between measurement systems distributed across the slope. The recorded AE rates have been used to derive cumulative displacements over time for the monitoring locations at Hollin Hill. Field trials of the Slope ALARMS monitoring approach at Hollin Hill and other sites are on-going and validation against continuous deformation data is expected in the near future.

\section{Acknowledgements}

We would like to extend our sincerest gratitude to Steve and Josie Gibson (the Hollin Hill landowners) for their support and cooperation in the research. This paper is published with the permission of the Executive Director of the British Geological Survey (NERC).

\section{References}

Allison, R J, and D Brunsden. 1990. Some Mudslide Movement Patterns. Earth Surface

Processes and Landforms 15: 297-311. 
Chambers, J.E. Weller, A.L. Gunn, D.A. Kuras, O. Wilkinson, P.B. Meldrum, P.I. Ogilvy, R.D. Jenkins, G.O. Gibson, A.D. Ford, J.R. \& Price, S.J. 2008. Geophysical Anatomy of the Hollin Hill Landslide, North Yorkshire, UK Near Surface 2008 - 14th European Meeting of Environmental and Engineering Geophysics, Poland, September, pp5.

Chambers, J.E, P.B Wilkinson, O Kuras, J.R Ford, D.A Gunn, P.I Meldrum, C.V.L Pennington, A.L Weller, P.R.N Hobbs, and R.D Ogilvy. 2011. Three-dimensional Geophysical Anatomy of an Active Landslide in Lias Group Mudrocks, Cleveland Basin, UK. Geomorphology 125 (4): 472-484.

Dixon, N. Hill, R. \& Kavanagh, J. 2003. Acoustic emission monitoring of slope instability: Development of an active wave guide system. Institution of Civil Engineers Geotechnical Engineering Journal, 156, 2, 83-95.

Dixon, N. \& Spriggs, M. 2007. Quantification of slope displacement rates using acoustic emission monitoring. Canadian Geotechnical Journal, 44, 6, 966-976.

Dixon, N., Spriggs, M.P., Meldrum, P., Ogilvy, R., Haslam, E. \& Chambers, J. 2010. Development of a low cost acoustic emission early warning system for slope instability. Proceedings $11^{\text {th }}$ International Association of Engineering Geologists, Editors Williams, A.L., Pinches, G.M., Chin, C.Y., McMorran, T.J. \& Massey, C.I. Taylor and Francis Pubs, Auckland, September, 1803-1810.

Dixon, N. \& Spriggs, M. 2011. Apparatus and method for monitoring soil slope displacement rate. UK Patent Application GB 2467419A, Awarded May 2011.

Dixon, N, M P Spriggs, P Meldrum, and E Haslam. 2012. Field Trial of an Acoustic Emission Early Warning System for Slope Instability. In Landslides and Engineered Slopes: Protecting Society Through Improved Understanding, 1399-1404.

Dunnicliff, J. 1988. Geotechnical instrumentation for monitoring field performance, John Wiley \& Sons, pp 577. 
Fujiwara, T, A Ishibashi, and K Monma. 1999. Application of Acoustic Emission Method to Shirasu Slope Monitoring. In Slope Stability Engineering, Yagi, Yamagami \& Jiang, Balkema, Rotterdam, 147-150.

Gunn, D A, J E Chambers, P R N Hobbs, J R Ford, P B Wilkinson, G O Jenkins, and A Merrit. 2013. Rapid Observations to Guide the Design of Systems for Long-Term Monitoring of a Complex Landslide in the Upper Lias Clays of North Yorkshire, UK. Quarterly Journal of Engineering Geology and Hydrogeology 46 (3): 323-336.

Hutchinson, J N. 1988. General Report: Morphological and Geotechnical Parameters of Landslides in Relation to Geology and Hydrogeology. In Proc 5th International Symposium on Landslides, Lausanne, 3-35.

Koerner, R.M. McCabe, W.M. \& Lord, A.E. 1981. Acoustic emission behaviour and monitoring of soils. In Acoustic Emission in Geotechnical Practice, ASTM STP 750, pp. 93-141.

Leroueil, S. 2001. Natural Slopes and Cuts: Movement and Failure Mechanisms. Geotechnique 51 (3): 197-243.

Lockner, D. (1993). The Role of Acoustic Emission in the Study of Rock Fracture. International Journal of Rock Mechanics and Mining, 30(7), 883-899.

Maji, A. K., Satpathi, D., \& Kratochvil, T. (1997). Acoustic emission source location using lamb wave modes. Journal of engineering mechanics, 123, 154-161.

Massey, C I, D N Petley, and M J McSaveney. 2013. Patterns of Movement in Reactivated Landslides. Engineering Geology 159: 1-19.

Matsuura, S, S Asano, and T Okamoto. 2008. Relationship Between Rain And/or Meltwater, Pore-water Pressure and Displacement of a Reactivated Landslide. Engineering Geology 101: 49-59. 
Merritt, A.J, J.E Chambers, W Murphy, P.B Wilkinson, L.J West, D.A Gunn, P.I Meldrum, N Kirkham and N. Dixon. 2013. 3D Ground Model Development for an Active Landslide in Lias Mudrocks Using Geophysical, Remote Sensing and Geotechnical Methods. Landslides, pp 14. DOI 10.1007/s10346-013-0409-1

Michlmayr, G., Cohen, D., \& Or, D. (2012). Sources and characteristics of acoustic emissions from mechanically stressed geologic granular media - A review. Earth-Science Reviews, $112,97-114$.

Michlmayr, G., Cohen, D., \& Or, D. (2013). Shear-induced force fluctuations and acoustic emissions in granular material. Journal of Geophysical Research: Solid Earth, 118(12), 6086-6098.

Nakajima, I., Negishi, M., Ujihira, M., \& Tanabe, T. (1991). Application of the acoustic emission monitoring rod to landslide measurement. 5th conference on acoustic emission / microseismic activity in geologic structures and materials (pp. 1-15).

Petley, D N, F Mantovani, M H Bulmer, and A Zannoni. 2005. The Use of Surface Monitoring Data for the Interpretation of Landslide Movement Patterns. Geomorphology 66: 133-147.

Petley, D N. 2012. Global Patterns of Loss of Life from Landslides. Geology, Geological Society of America 40 (10): 927-930.

Pollard, H. (1977). Sound waves in solids (pp. 6-60).

Shiotani, T. \& Ohtsu, M. 1999. Prediction of slope failure based on AE activity. In Acoustic Emission: Standards and Technology update (Vahaviolos, S.J. (Ed.)), American Society for Testing Materials, ASTM STP, Pennsylvania, 1353, pp. 157-172.

Schulz, William H, Jason W Kean, and Gonghui Wang. 2009. Landslide Movement in Southwest Colorado Triggered by Atmospheric Tides. Nature Science Advance on: 1-4. 
Schuster, R.L. \& Krizek, R.J. (eds.) 1978. Landslides Analysis and Control, Transportation Research Board Special Report 176, National Academy of Science, Washington.

Spriggs, M. P. (2005). Quantification of acoustic emission from soils for predicting landslide failure. PhD thesis, Civil and Building Engineering, Loughborough University, UK. 


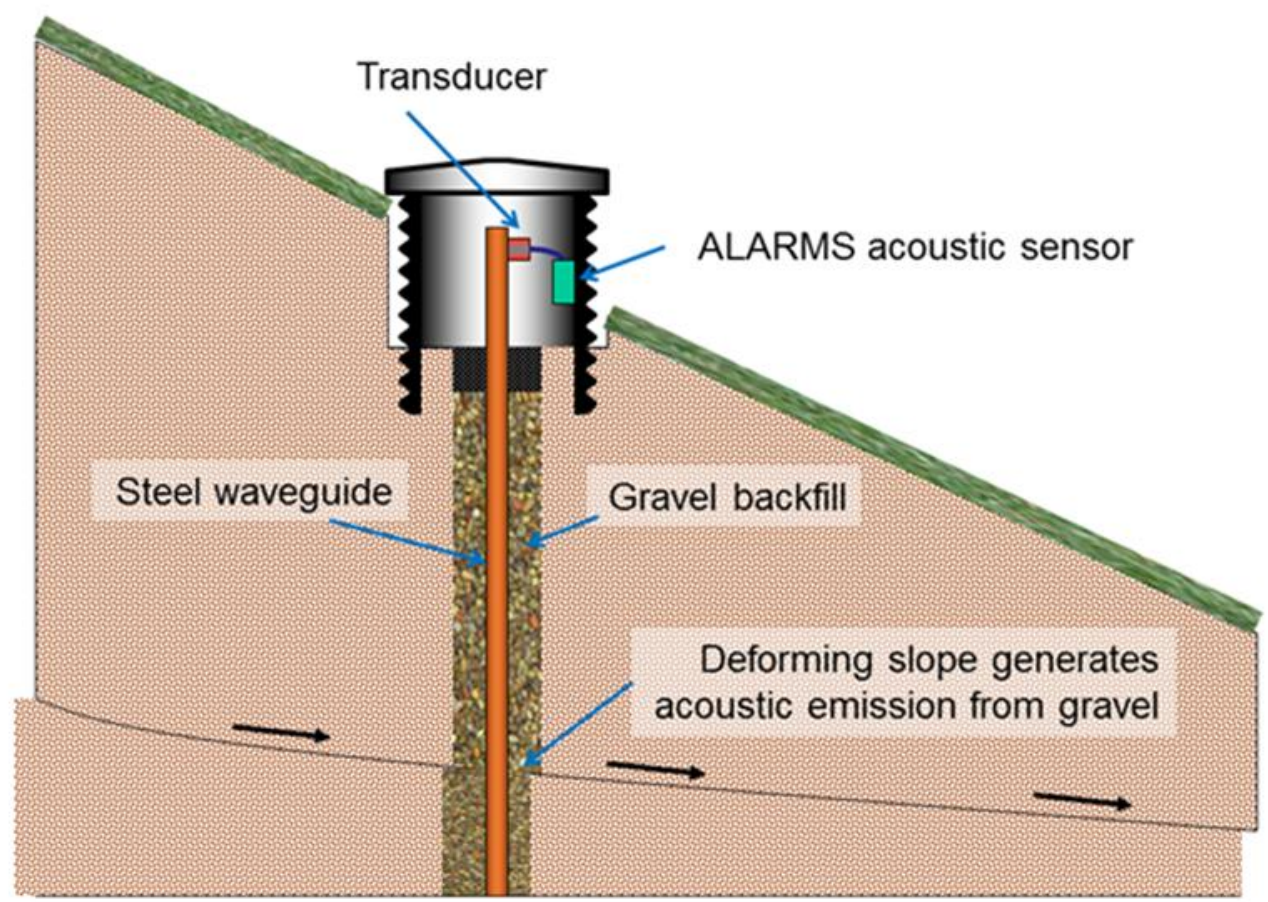

Fig. 1 Schematic of an active waveguide installed through a slope deforming on a shear plane, with AE monitoring sensor attached to the top of the waveguide and protected by a cover (after Dixon et al. 2012) 
a)

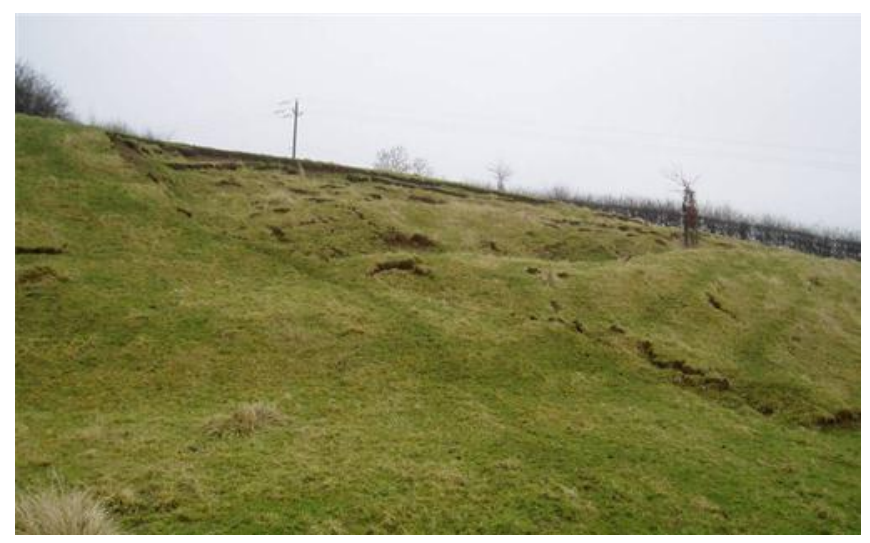

b)

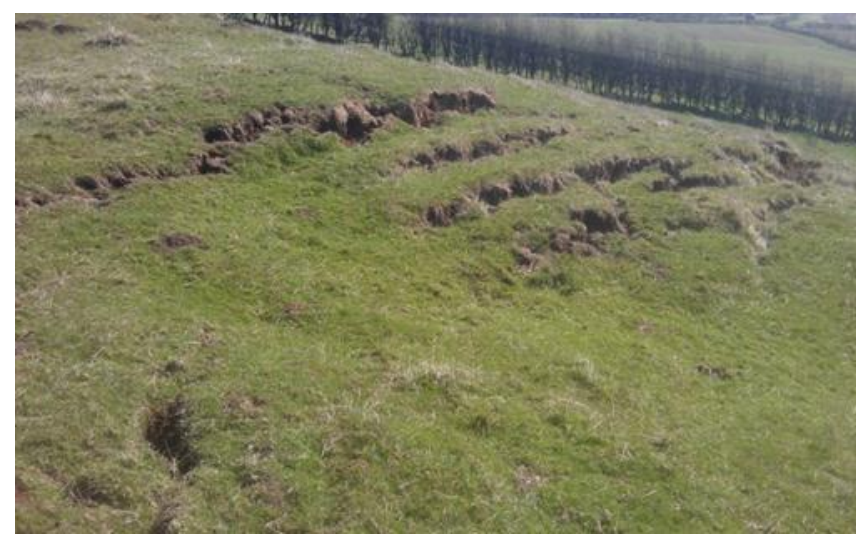

Fig. 2 a) Rotational sliding in the upper part of the slope, and b) materials degrading and forming lobes sliding down the lower part of the slope

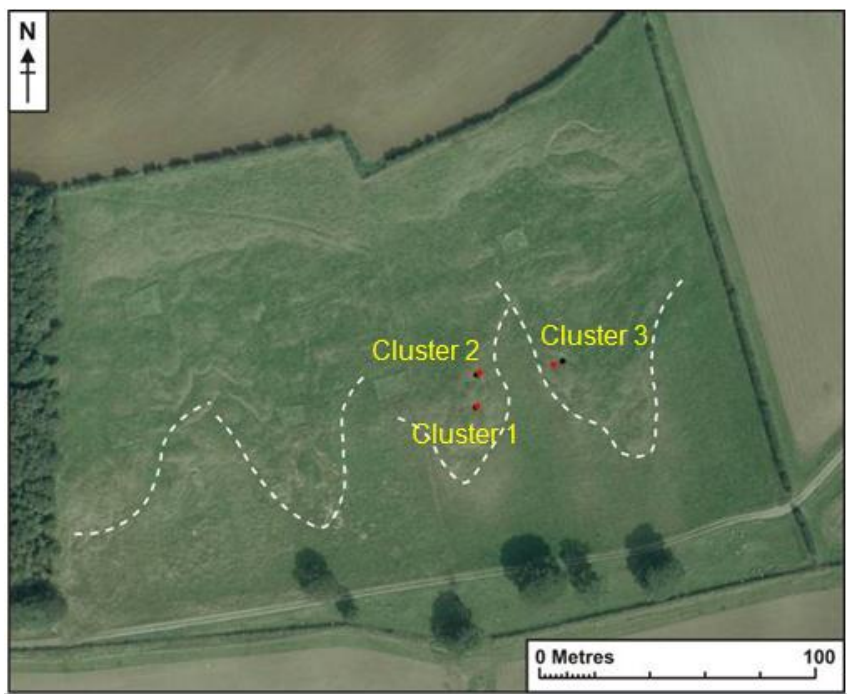

Fig. 3 Outline of active lobes in the lower part of the slope and the location of the three clusters of instruments, each comprising a pair of AE waveguides and inclinometer castings. Clusters 1 and 2 on the western lobe and cluster 3 on the eastern lobe (C) UKP/Getmapping Licence No. UKP2008/01) 


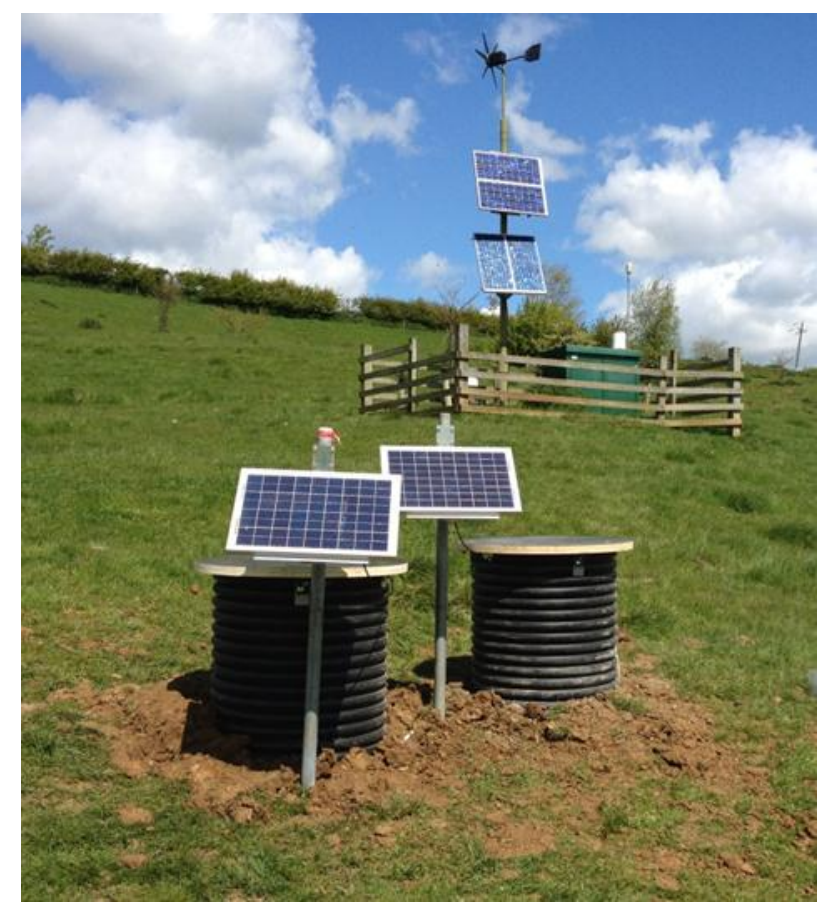

Fig. 4 Two waveguide assemblies with covers and solar panels installed on the western lobe (Cluster 2). The BGS ERT instrument compound can be seen up slope of the waveguides 
a)

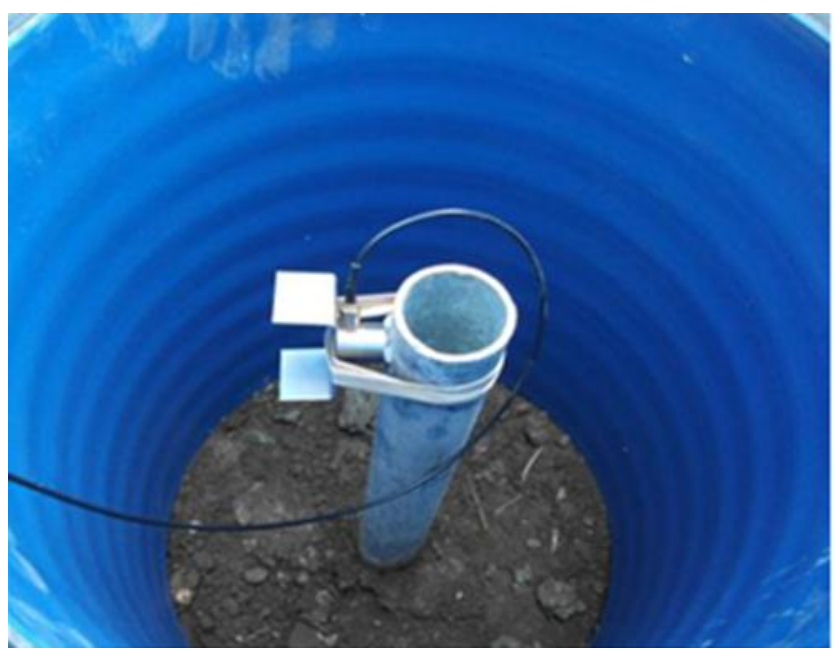

b)

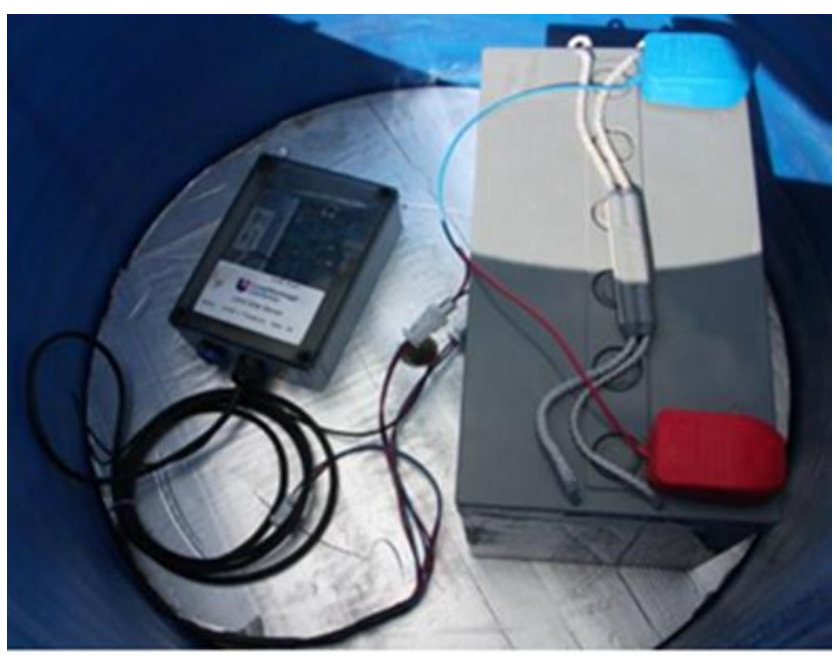

Fig. 5 a) Waveguide with piezoelectric transducer attached, and b) AE sensor and battery inside cover 


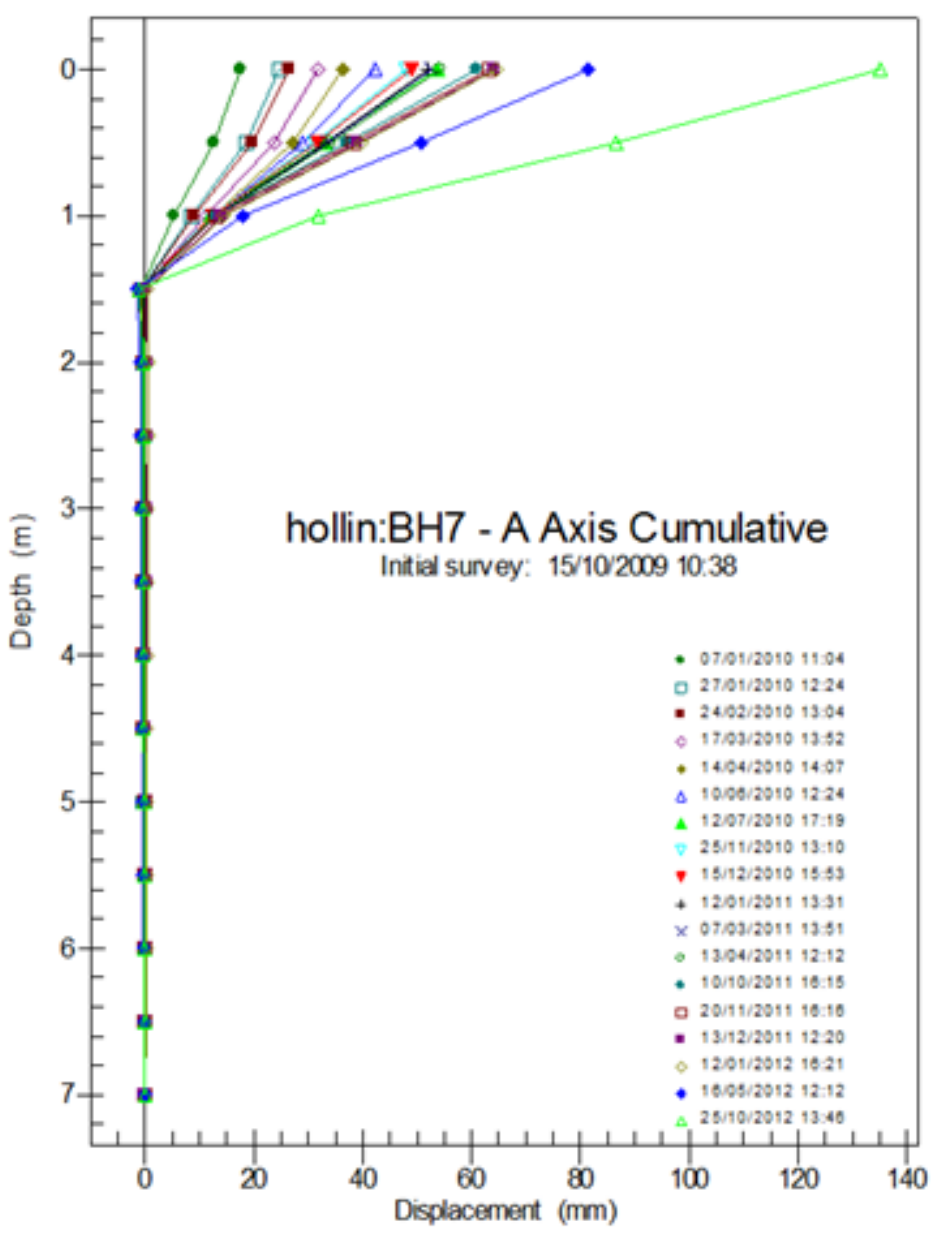

Fig. 6 Selected surveys of the inclinometer casing at Cluster 1 western flow lobe between January 2010 and October 2012 showing a shear plane at a depth of $1.0 \mathrm{~m}$ to 1.5 metres below ground level and sporadic periods of deformations that are in response to periods of rainfall 


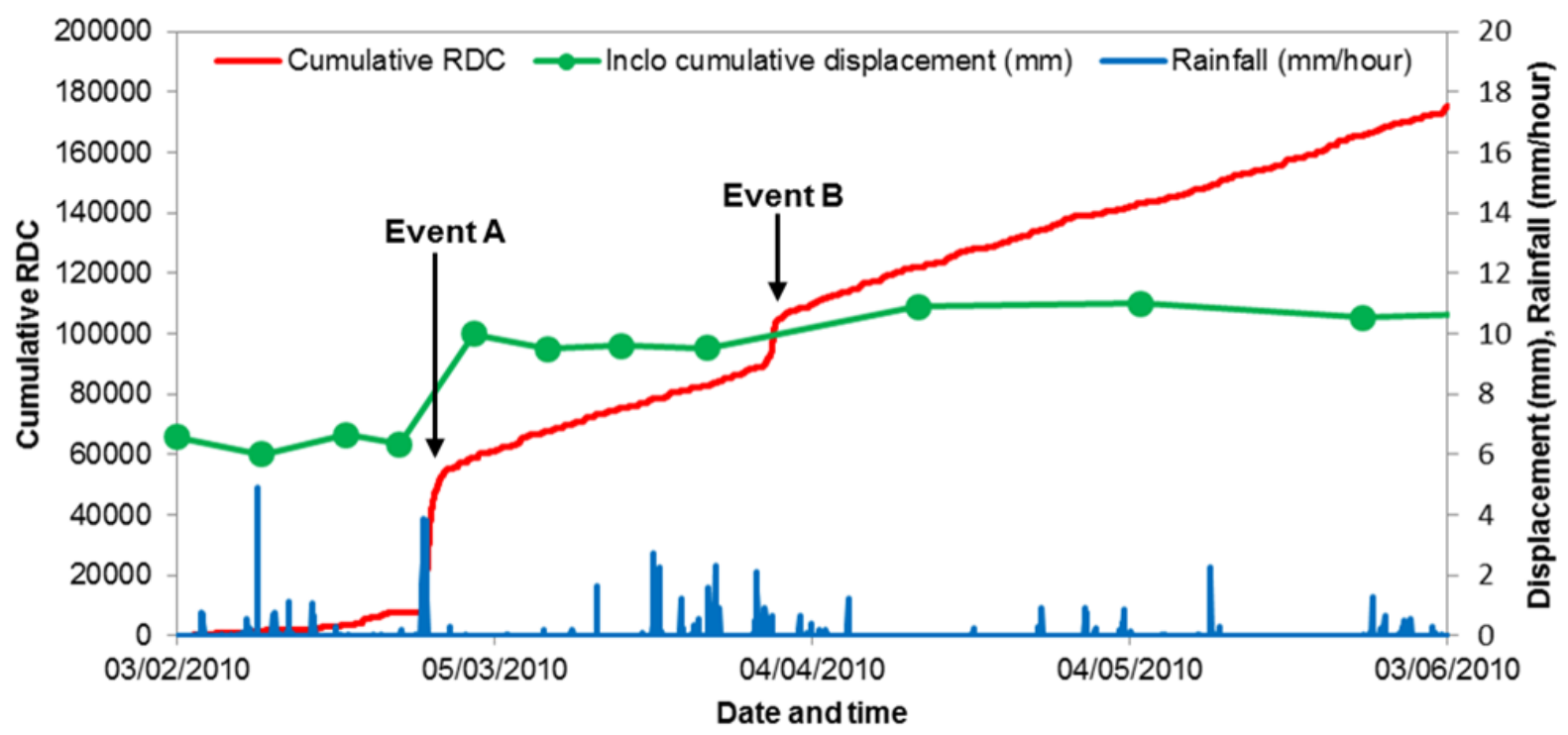

Fig. 7 ' $S$ ' shaped cumulative RDC curves defining periods of slope deformation at Cluster 2 and validated by inclinometer measurements. Events 1 and 2 are highlighted

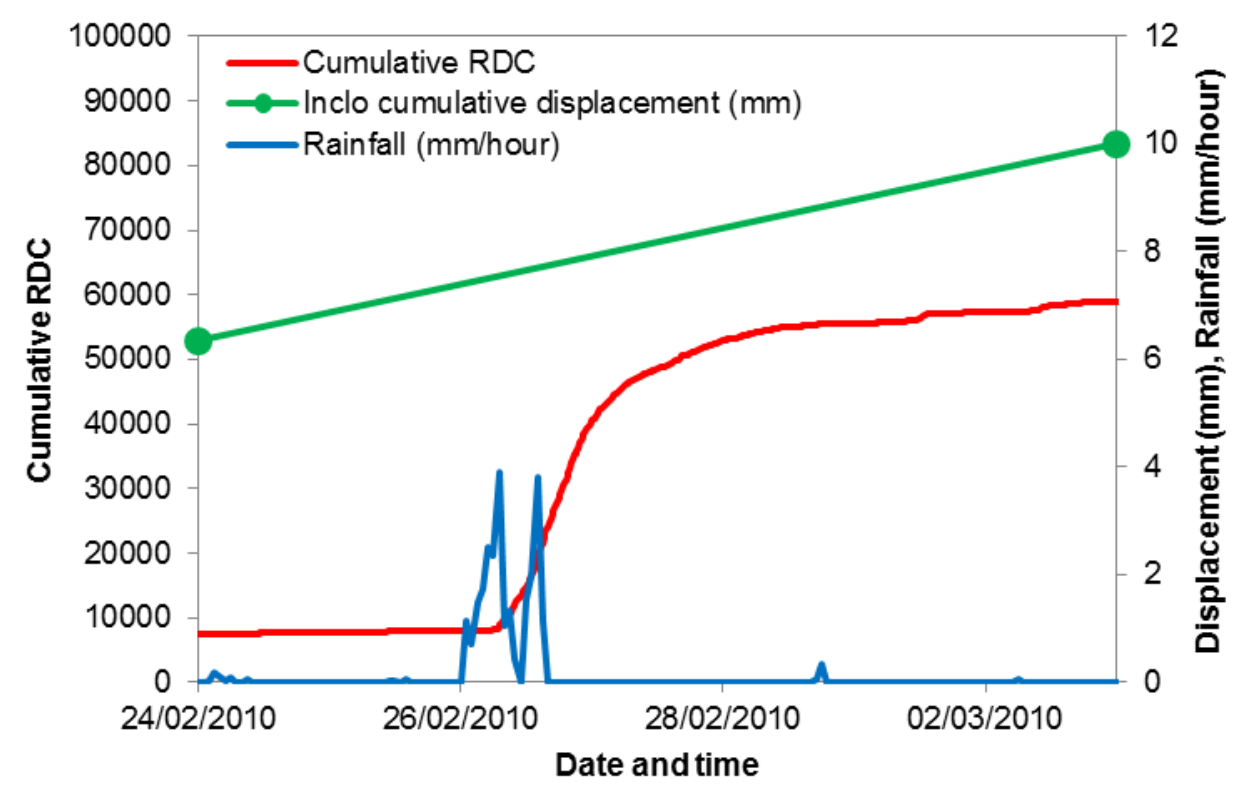

Fig. 8 Cumulative RDC, triggering rainfall event and measured displacements for Event A at Cluster 2 


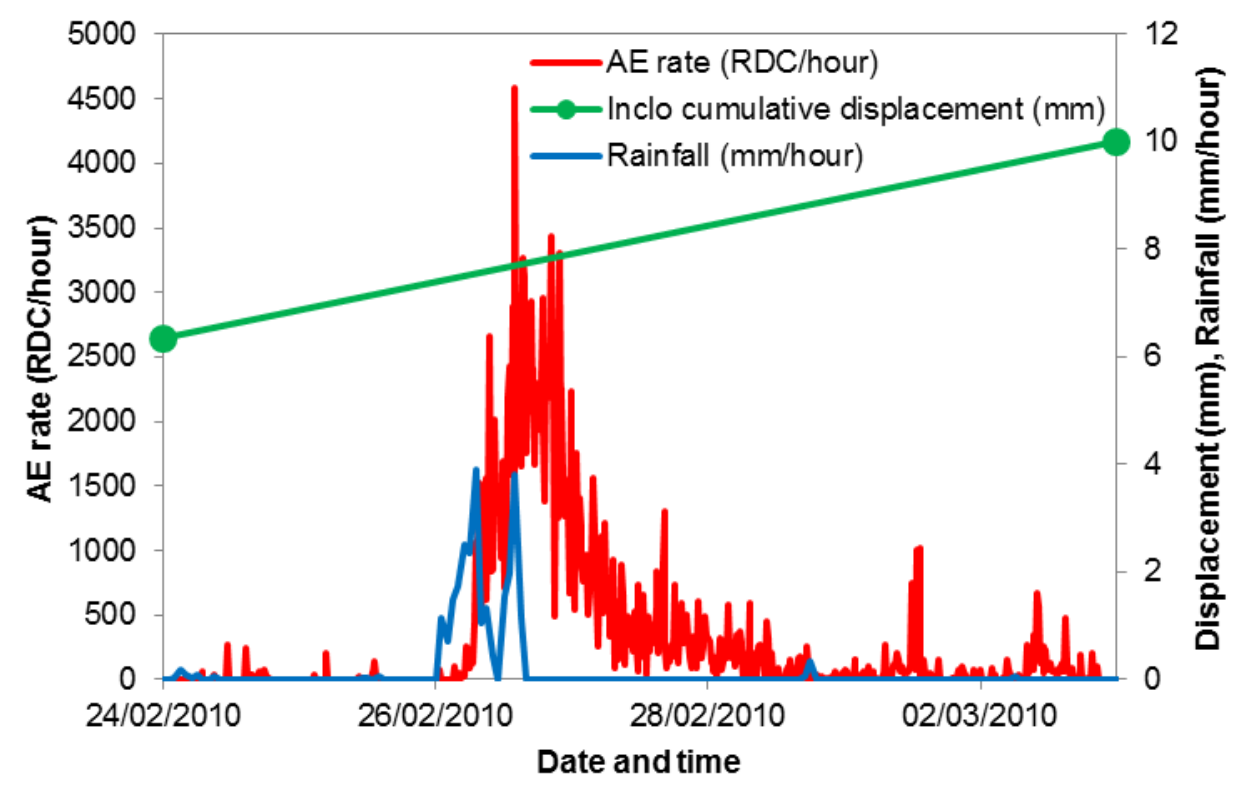

Fig. $9 \mathrm{AE}$ rate (RDC/hour), triggering rainfall event and measured displacements for Event A on Cluster 2

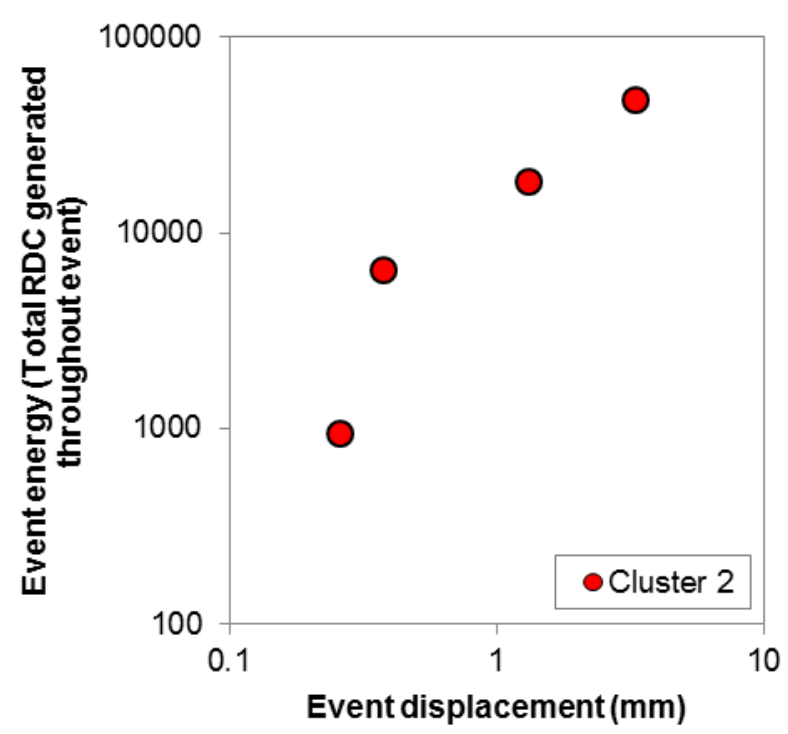

Fig. 10 Relationship between deformation event AE energy (total RDC generated throughout event) and event cumulative slope displacement magnitude for Cluster 2 plotted on log-log scales 


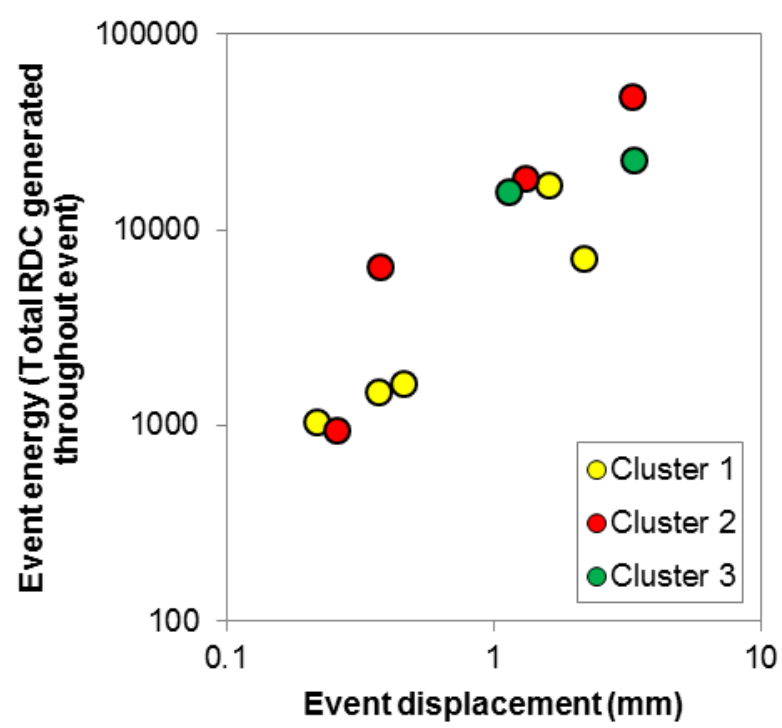

Fig. 11 Relationship between deformation event AE energy (total RDC generated throughout event) and event cumulative slope displacement magnitude for Clusters 1, 2 and 3 plotted on $\log -\log$ scales

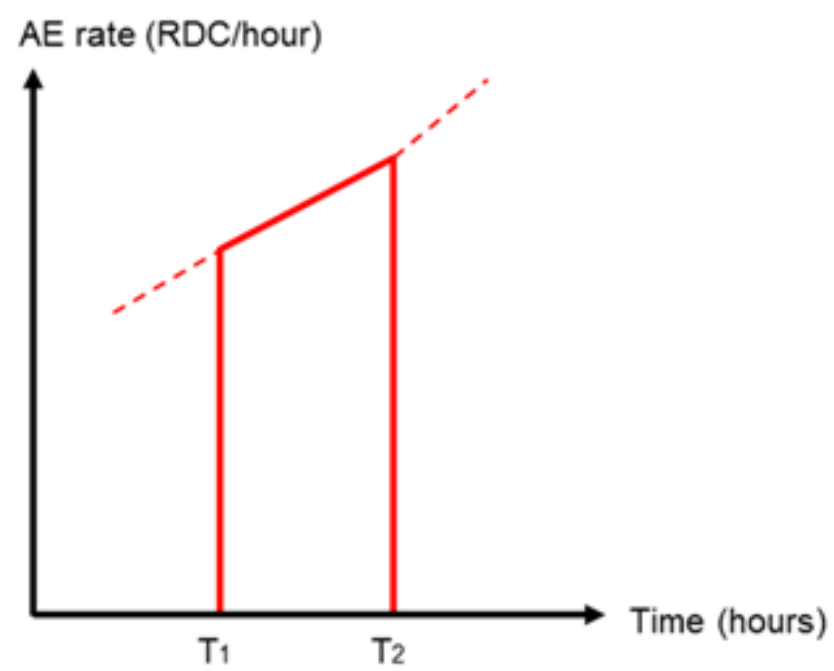

Fig. 12 Trapezoidal interrogation of AE rate data to obtain incremental event velocity from the displacement/time relationship 


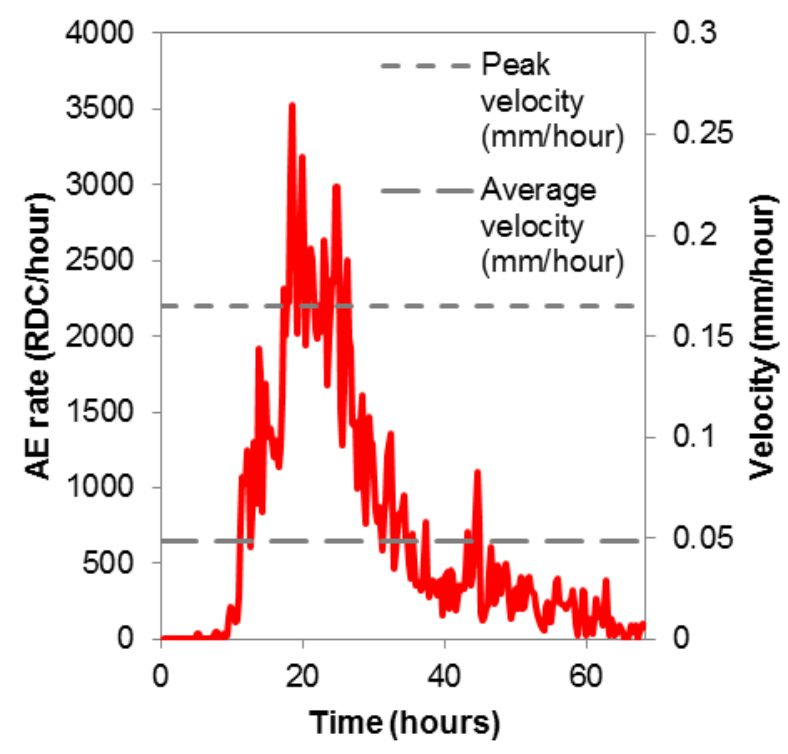

Fig. 13 AE rate and derived velocity for Event A at Cluster 2

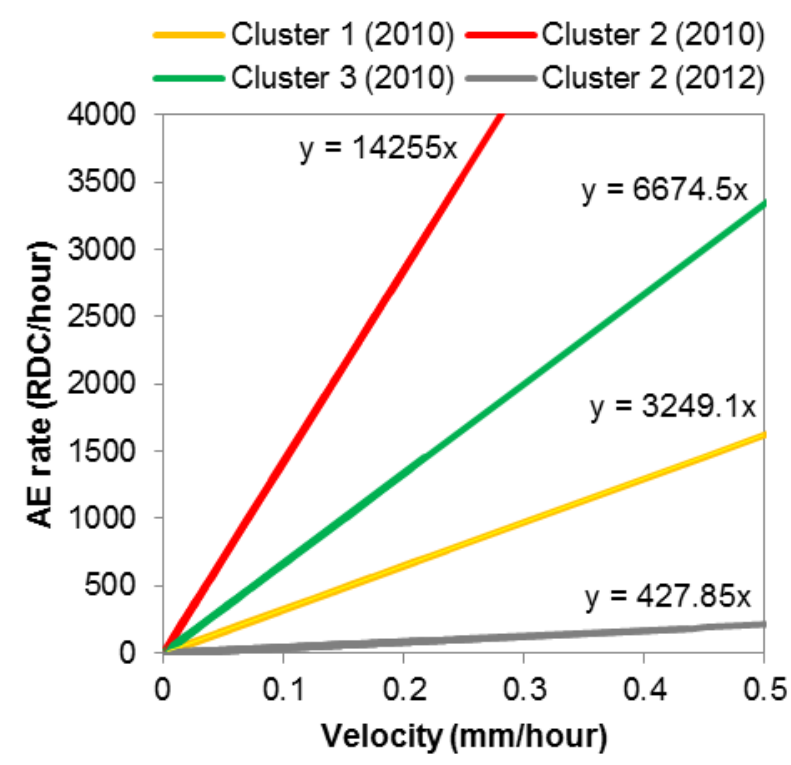

Fig. 14 AE rate-velocity calibration relationships for events on different systems over the course of monitoring at the Hollin Hill site 


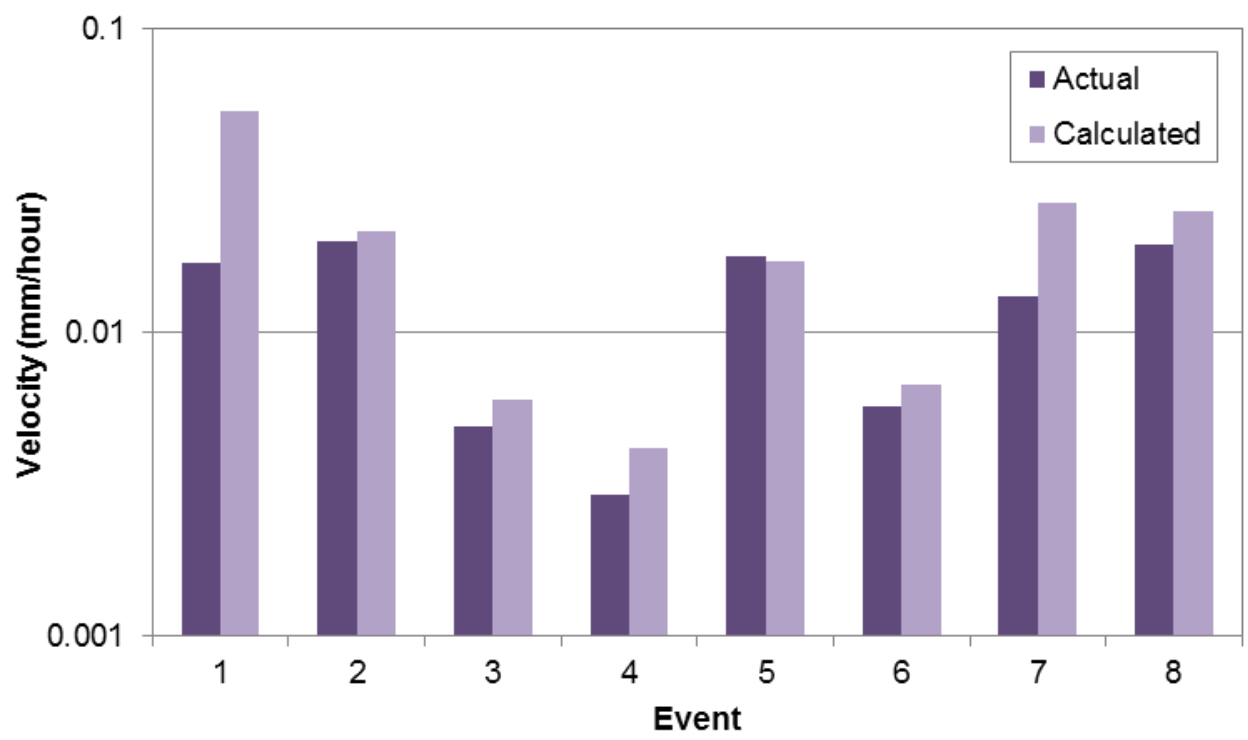

Fig. 15 Comparison of measured slope deformation event velocities and those calculated from the $\mathrm{AE}$ rates

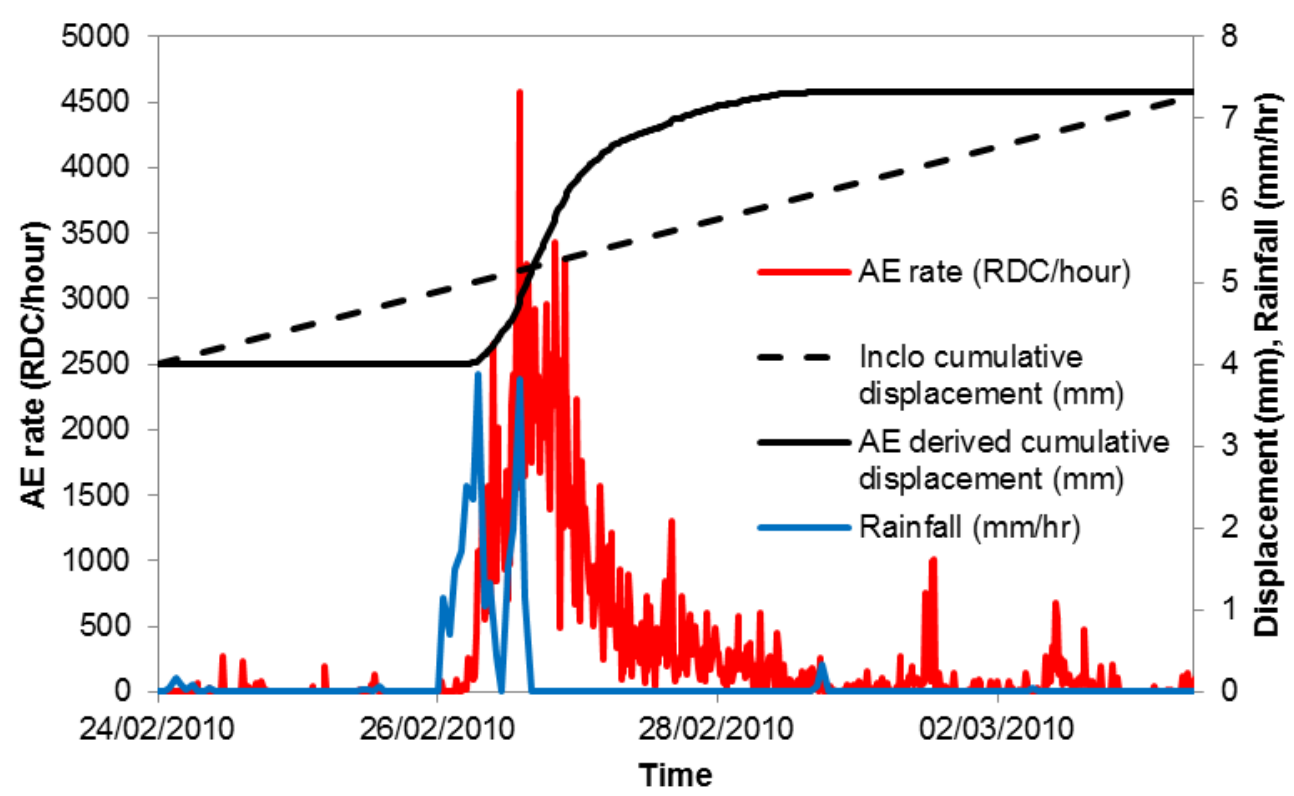

Fig. 16 Derivation of cumulative displacements from AE measurements for Event A on Cluster 2 


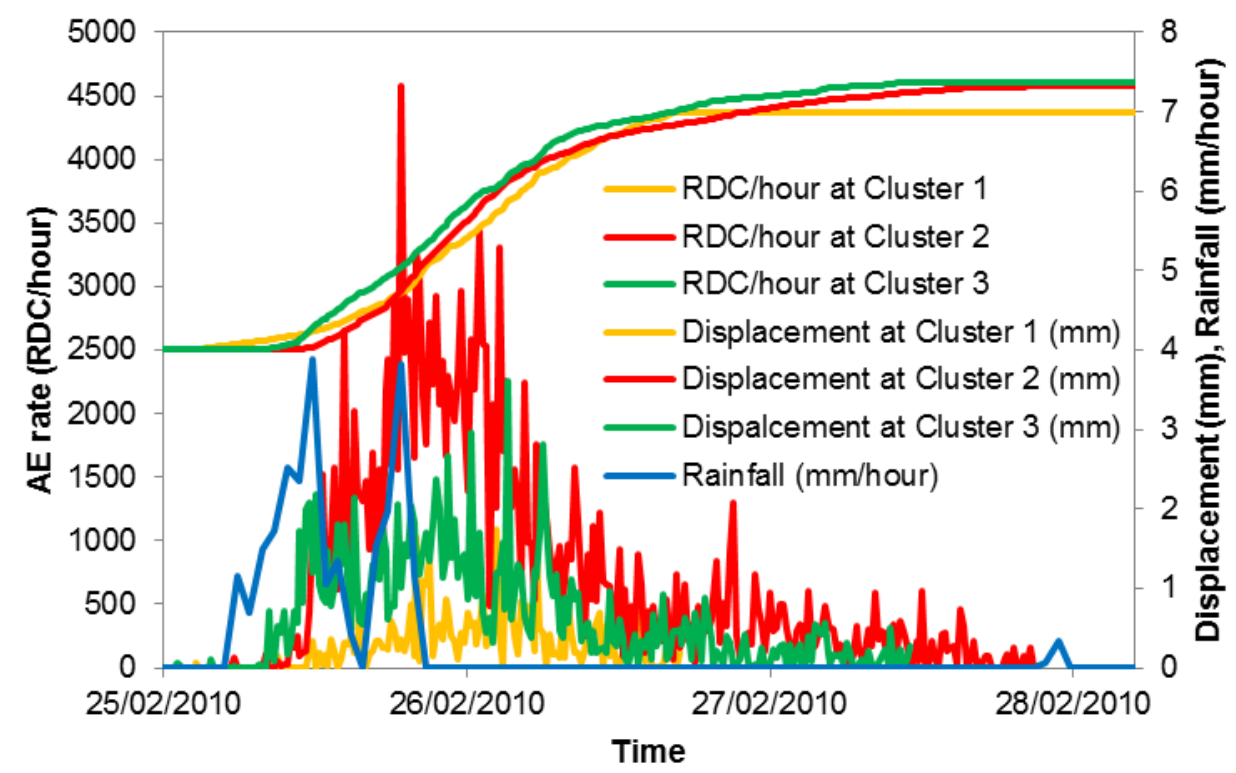

Fig. 17 AE responses of all three clusters to a rainfall event and the derived slope cumulative displacements at each location 